\title{
Sleep-Scheduling Strategies in Hospital Shiftworkers
}

\author{
Elizabeth $M$ Harrison (iD) \\ Alexandra P Easterling ${ }^{\prime}$ \\ Abigail M Yablonsky² \\ Gena L Glickman',3 \\ 'Center for Circadian Biology, University \\ of California San Diego, La Jolla, CA, \\ USA; ${ }^{2}$ Naval Medical Center San Diego, \\ San Diego, CA, USA; ${ }^{3}$ Uniformed \\ Services University of the Health \\ Sciences, Bethesda, MD, USA
}

Correspondence: Elizabeth M Harrison Center for Circadian Biology, University of California San Diego, 9500 Gilman Dr, La Jolla, CA, 92093, USA

$\mathrm{Tel}+$ I 619-736-1532

Email emharrison@ucsd.edu
Introduction: Shiftwork causes circadian disruption and results in impaired performance, sleep, and health. Often, individuals on non-standard shifts cannot modify work schedules. Athome sleep schedules are a potentially modifiable point of intervention, yet sleep-scheduling strategies remain relatively understudied. Specifically, the adoption of multiple strategies and the employment of strategies for not only night shifts, but also early starts on days, have yet to be formally examined to our knowledge. We studied how adoption of specific and/or multiple sleepscheduling strategies for day and night shifts relates to measures of adaptation to shiftwork, selfreported on-shift sleepiness, and individual characteristics (eg, age, chronotype, education in circadian and sleep health). We hypothesized: 1) strategies would differ by shift type, 2) individuals would adopt multiple strategies, 3 ) strategies better aligned with circadian principles would relate to measures of adaptation, and 4) individual characteristics, such as having dependents, would relate to strategy selection.

Methods: A retrospective, online questionnaire (including items from the Survey of Shiftworkers and items related to sleep-scheduling strategies) was administered to both permanent and rotating hospital staff in four wards working 12-h day and/or night shifts $(\mathrm{n}=89)$. Additionally, reasons for strategy selection were explored.

Results: Level of adaptation varied by sleep-scheduling strategy, with the least adaptation for those utilizing the Incomplete Shifter strategies. For night shifts, Night Stay and Switch Sleeper-N strategies were related to lower mid-shift sleepiness. Many night workers reported using strategies that restricted sleep, and most reported using multiple strategies, both of which also related to lower adaptation. Domestic considerations were the most common rationale for strategy selection. Strategies varied by several individual characteristics, including chronotype, dependents, and level of sleep education.

Discussion: Future work should investigate sleep strategies and circadian interventions to help mitigate the effects of circadian and sleep disruption in hospital staff.

Keywords: circadian, alertness, naps, nurses, military

\section{Introduction}

The practice of shiftwork is prevalent and has deleterious short- and long-term effects on sleep, health, and performance, ${ }^{1,2}$ as it results in both circadian disruption and chronic sleep restriction. Indeed, even "permanent" night workers largely fail to adapt physiologically to their schedules, owing in part to the conflicting light signals their circadian systems receive upon leaving work in the morning and on their days off. ${ }^{2,3}$ Furthermore, night workers typically report more sleep disturbance than day workers. ${ }^{4}$ Internal, environmental, and social rhythms all play a role: 1) myriad biological processes, including alertness, fluctuate in a circadian manner that inhibits daytime sleep, 2) environmental factors, such as light intensity, temperature and noise levels, tend to be higher during daylight hours and 3) familial, 
occupational, and educational responsibilities typically occur during the day, interrupting sleep opportunities.

Rotating shiftworkers must also contend with both circadian disruption and restricted sleep as a result of alternating between different shift types. Additionally, a growing body of evidence suggests that day shifts, which are commonly used as control conditions and considered to be one of the easiest shift types, also result in sleep, alertness, and performance decrements. ${ }^{5-7}$ As all shiftwork, then, necessarily carries with it some disruption, circadian realignment and/or improvements in sleep are common targets of intervention in shiftworking populations. While this could theoretically include changes in shift scheduling practices, individuals often have little to no control over their work hours, particularly early on in their careers. ${ }^{7}$ At an organizational level, institutions may be averse to changing the status quo for a variety of reasons, from financial or industry-specific concerns to simple inertia. ${ }^{8}$ Thus, it is often more practical to focus on behavioral strategies and interventions. ${ }^{9}$ In particular, implementation of deliberate sleep-scheduling strategies may be a cost-free means to facilitate adaptation in the absence of the ability to change work schedules themselves. Examining rationales for sleep strategy selection might also help determine how much, in fact, sleep schedules are under volitional control. While sleep is volitional to a degree, the phase or timing of sleep relative to the body's internal rhythms is an important determinant of the quantity and quality of that sleep, ${ }^{10}$ as is the duration of (and time elapsed since) an individual's last sleeping period. $^{11}$

One of the most commonly recommended sleepscheduling strategies is napping. Naps can be used prophylactically before or during a night shift to prevent the accumulation of sleep pressure during the shift, thereby improving subsequent alertness. ${ }^{12}$ They have also been recommended post-shift before the commute home, a particularly dangerous time for night workers in terms of fatigue and driving incidents. ${ }^{13,14}$ Laboratory studies indicate that both the timing and duration of naps are critical for optimal effects. $^{15}$

A few other strategies based on the timing and/or duration of sleep have also received some attention. The concept of "banking" sleep (ie, sleeping more in anticipation of an upcoming period of restricted sleep) is emerging as an effective strategy to improve performance acutely, ${ }^{16,17}$ though long-term effects on sleep and other health outcomes remain uninvestigated. Apparently at odds with this strategy, many recommendations for good sleep practices include keeping a consistent schedule. ${ }^{18}$ This is also supported by much of circadian theory, and a new body of evidence suggests regularity of sleep timing is important for positive longer-term cognitive outcomes in young adults. ${ }^{19,20}$ Thus, here emerges an example of the many balances shiftworkers must strike, whether consciously or not: a choice between prioritizing longer sleep duration and maintaining consistent sleep timing.

Most sleep research conducted in a laboratory setting aims to control for, or manipulate, sleep timing, but there is not a lot of literature directly comparing sleep timing choices in field settings. Many studies have characterized "typical" or average sleeping patterns on different shifts, on work days vs days off, ${ }^{21-23}$ or on different schedules, such as with earlier or later start times. ${ }^{4,5}$ Others have found individual characteristics, such as chronotype and sleep "flexibility", relate to improved outcomes from a particular sleep-scheduling strategy - napping. ${ }^{24,25}$ However, the efficacy of certain sleep-scheduling strategies per se has only been examined in actual workplaces in a limited fashion. Some shiftworker studies have compared sleep quality across day- vs night-time sleep on the same work schedule, ${ }^{26,27}$ or examined limited measures of regularity of sleep timing and adaptation of shiftworkers. $^{22,28}$ One such study also specifically examined rates of employing certain sleep-scheduling strategies, such as going to bed earlier when working early morning shifts, or trying to get a few hours of "anchor" sleep on days off of night shifts (near the time they would be sleeping on work days). ${ }^{22}$

The two most comprehensive and rigorous studies of sleep-scheduling strategies were conducted by the same research team, and stratified workers by a single strategy based on self-reported predicted sleeping times when working night shifts. $^{29,30}$ Both studies, by and large, found that adoption of the "Incomplete Shifter" strategy, one that shifts part way between diurnal and nocturnal sleeping on days off, related to subjective measures of adaptation on night shifts. These studies, while informative, did not consider the adoption of multiple sleepscheduling strategies by the same person, which could vary as a function of schedule variations, leisure activities, or outside responsibilities. Further, no study to our knowledge has investigated the efficacy of sleep-scheduling strategies for day workers, though converging evidence suggests that those working daytime shift schedules could benefit from shiftwork interventions due to both 
long work hours and early start times. ${ }^{5,6}$ Finally, there is no research examining sleep-scheduling strategies in a military setting, wherein risk for sleep and circadian disruption, as well as physical and psychological health issues, are significantly increased. ${ }^{31-34}$ We therefore sought to examine how adoption of specific and/or multiple sleep-scheduling strategies for both day and night shifts relates to measures of adaptation to shiftwork schedules, self-reported sleepiness on shift, as well as individual characteristics in shiftworking hospital staff in a US Navy Medical hospital. Additionally, rationales for strategy selection, such as domestic life and commute, were explored.

We hypothesized that sleep strategies would vary by shift type and that individuals were likely to adopt more than one sleep-scheduling strategy, rather than endorsing a single, primary strategy; however, those on permanent schedules may be more likely than rotating shiftworkers to employ a single strategy. Additionally, we predicted that strategies with the least amount of circadian disruption and/or the longest sleep opportunities would relate to better self-reported adaptation. Finally, we also suspected certain individual characteristics might influence sleep-scheduling strategy selection. For example, participants with partners or dependents may find staying on a night-oriented schedule, even on days off, less feasible than those without, and may therefore adopt those strategies less frequently. Additionally, those with more training or knowledge about sleep and/or motivation to change sleep behavior may be less inclined to adopt strategies with more timing variability or strategies that forego sleep, such as those that require staying up all night before the first night shift. Further, certain job characteristics might be associated with certain strategies (eg, individuals who work more night shifts may adopt different strategies than those who work nights only occasionally). Finally, other individual characteristics that have been associated with sleep quality and/or adaptation to shiftwork might also be associated with certain strategies (eg, younger age, eveningness, and more sleep "flexibility" might relate to more variable or "flexible" sleep strategies). ${ }^{24,35}$

\section{Materials and Methods}

\section{Scheduling Practices}

Nursing staff at the hospital worked primarily $12 \mathrm{~h}$ shifts in a slow, rotating variant of a "blocked" 2-3-2 shift schedule ( 2 days on, 3 off, 2 on; 2 days off, 3 on, 2 off), with occasional deviations for additional coverage or sick days. Under this schedule, staff would have one "long" week with more shifts and one "short" week with fewer, across each two-week period. Most individuals alternated between days and nights (0700-1900 and 1900-0700, respectively) approximately every 6 weeks. Permanent schedules also occurred but were far less common. Survey data were collected between August 2017 and the first week of February of 2020. The study protocol and all procedures were approved by the Naval Medical Center San Diego Institutional Review Board (NMCSD.2012.0002) in compliance with all applicable federal regulations governing the protection of human subjects and in accordance with the principles stated in the Declaration of Helsinki. All participants provided informed written consent.

\section{Recruitment}

Participants were recruited by civilian study staff via email and in-person during shift turnovers. After completing the questionnaire, participants were given the opportunity to provide contact information if they were interested in participating in a circadian lighting intervention that has been presented in part elsewhere. ${ }^{36,37}$ Eighty-nine staff members completed the survey, which took approximately 20 minutes to complete. Participant demographic characteristics are described in Table 1.

\section{Measures}

Participants were administered the questionnaire via anonymous, online link (Qualtrics; Seattle, WA). The majority of the questionnaire consisted of two validated assessments: 1) the reduced version of the Morningness Eveningness Questionnaire (rMEQ), ${ }^{38,39}$ and 2) select subscales from the Survey of Shiftworkers (SoS), a retrospective tool designed to examine sleep and health in shiftworkers. ${ }^{40,41}$ This included the validated Alertness Scales, modified from the Karolinska Sleepiness Scale (KSS) to retrospectively measure sleepiness on a scale from 1 to 9 across typical work shifts $(1=$ Very Alert, $3=$ Alert, 5= Neither alert nor sleepy, $7=$ Sleepy (but not fighting sleep) and $9=$ Very sleepy (fighting sleep)). ${ }^{42}$ Participants were instructed to only complete items for shift types they had worked in the last 6 months. 
Table I Demographic Composition and Chronotype

\begin{tabular}{|l|l|}
\hline Participant Characteristics & Mean (SD) \\
\hline Age, y & $30.13(9.78)$ \\
\hline Shiftwork, y & $6.13(7.84)$ \\
\hline & $\mathrm{N}(\%)$ \\
\hline Gender: Female & $63(70.8)$ \\
\hline Nurse (RN) & $48(53.9)$ \\
Corpsman & $34(38.2)$ \\
Administrator/Leader & $7(7.9)$ \\
\hline Active duty & $76(85.4)$ \\
Civilian & $13(14.6)$ \\
\hline Permanent Day & $16(18.0)$ \\
Permanent Night & $13(14.6)$ \\
Rotating & $60(67.4)$ \\
\hline Labor \& Delivery & $31(34.8)$ \\
Oncology/lnternal Medicine & $34(38.2)$ \\
Orthopedics & $24(27.0)$ \\
\hline White & $37(41.6)$ \\
Asian & $19(21.3)$ \\
Hispanic & $14(15.7)$ \\
Black & $12(13.5)$ \\
Multiple/Other & $7(7.8)$ \\
\hline Single & $35(39.3)$ \\
Married/Living with Partner & $46(51.7)$ \\
Separated/Divorced/Widowed & $8(9)$ \\
\hline Children in home (I or more) & $27(30.3)$ \\
Other dependent in home (I or more) & $6(6.7)$ \\
\hline Definitely Morning type & $9(10.1)$ \\
Moderately Morning type & $3.51 .7)$ \\
\hline Meither type & \\
Definitely Evening type & $30.3)$ \\
\hline
\end{tabular}

\section{Sleep-Scheduling Strategies}

For night shiftworkers, the self-reported sleep-scheduling strategies that were described in the study questionnaire were modeled after the five defined by Gamble and colleagues: ${ }^{29,30}$ 1) Night Stay, 2) No Sleep, 3) Switch Sleeper, 4) Incomplete Switcher, and 5) Nap Proxy. Definitions and exemplars for each strategy in Gamble et al were used to generate lay-person descriptions for the questionnaire, with a few notable differences (see Table 2). We sought to build upon their work by including one novel night sleep-scheduling strategy that had been subsumed under the
Table 2 Definitions of Sleep-Scheduling Strategies

\begin{tabular}{|c|c|}
\hline \multicolumn{2}{|c|}{ Dayshift Strategies } \\
\hline Consistent & $\begin{array}{l}\text { Going to bed and getting up at same time on BOTH } \\
\text { work days and off days }\end{array}$ \\
\hline $\begin{array}{l}\text { Switch Sleeper- } \\
\text { D }\end{array}$ & $\begin{array}{l}\text { Waking earlier on JUST your last morning off, so } \\
\text { that wake time is closer to wake time when } \\
\text { working days }\end{array}$ \\
\hline $\begin{array}{l}\text { Incomplete } \\
\text { Shifter-D }\end{array}$ & $\begin{array}{l}\text { On your days off, going to bed later than you would } \\
\text { when working days but earlier than when working } \\
\text { nights }\end{array}$ \\
\hline Napper & Taking naps when possible \\
\hline \multicolumn{2}{|c|}{ Nightshift Strategies } \\
\hline $\begin{array}{l}\text { Incomplete } \\
\text { Shifter-N* }\end{array}$ & $\begin{array}{l}\text { On your days off, going to bed later than you would } \\
\text { when working days but earlier than when working } \\
\text { nights }\end{array}$ \\
\hline No Sleep & $\begin{array}{l}\text { Waking up at your usual time and staying up } \\
\text { through the first night shift, with no nap }\end{array}$ \\
\hline Nap Proxy & $\begin{array}{l}\text { On the majority of days off, taking a nap }>I \text { h during } \\
\text { the time when you would normally sleep when } \\
\text { working nights }\end{array}$ \\
\hline Night Stay & $\begin{array}{l}\text { Sleeping in the daytime on BOTH work days and off } \\
\text { days }\end{array}$ \\
\hline $\begin{array}{l}\text { Switch Sleeper- } \\
N\end{array}$ & $\begin{array}{l}\text { Sleeping longer or later on JUST the last night off, } \\
\text { so that wake time is closer to wake time when } \\
\text { working nights }\end{array}$ \\
\hline Switch Napper & $\begin{array}{l}\text { Napping ONLY before the first night shift, but not } \\
\text { on other days }\end{array}$ \\
\hline
\end{tabular}

Notes: Incomplete Shifter and Switch Sleeper appear as shift sleep-scheduling strategies for both day and night shifts, represented as "-D" and "-N", respectively. *This strategy was named Incomplete Switcher in Gamble et al $2012^{30}$, and changed to Incomplete Shifter in Petrov et al $2014 .{ }^{29}$ A number of additional clarifications for the purposes of categorization were also added at that time.

Switch Sleeper category in Gamble's studies ${ }^{29,30}$ and had also been observed in our previous work. ${ }^{7}$ This strategy involved taking a nap only on the first night shift in a series, which we called the "Switch Napper" strategy.

We also hypothesized shiftworkers would likely use more than one strategy, and that strategies may change over time. For example, Daurat \& Foret ${ }^{26}$ found that shiftworkers sleep at different times before a single night shift as compared to when they sleep on the first in a series of night shifts. Thus, rather than having individuals report a single, predicted sleep pattern which would then get characterized by investigators into a single strategy type, ${ }^{29,30}$ we asked how frequently individuals employed each strategy personally. Items for all 6 strategies for night 
shifts were pilot-tested with the Emergency Department, and scales were modified slightly as a result (data not included). Additionally, four novel sleep-scheduling strategies for day workers were also developed, conceptually consistent with the night strategies, where possible. See Table 2 for all 10 sleep strategies (4 days, 6 nights) and their definitions. Strategies that could theoretically be exercised for either Day or Night schedules are appended with a "-D" for day shifts or a "-N" for night shifts.

For both day and night sleep-scheduling strategies, participants reported the frequency of engaging in each: 0 = "I never do this", 1 = "I rarely do this", 2 = "I sometimes do this", 3 = "I frequently do this", 4 = "My most frequent strategy". If responses were provided for some strategies but not others, blanks were treated as 0 , or "I never do this." When possible, the most frequent strategy was calculated for each individual (in some cases, "ties" between multiple strategy types prohibited this). An additional, open-ended question was included in case individuals did not feel that the options represented any of their current sleep-scheduling strategies:

If you have a particular schedule of sleeping that involves napping, sleeping in chunks of time, or other shift-specific pattern not captured in the questions above, please describe it in as much detail as possible in the field below.

Finally, we added explicit items examining the considerations for employing sleep-scheduling strategies, adapted to match language from the SoS interference items (leisure, domestic, and non-domestic life; described below), and to also include "commute" and "other" categories.

Questions were also developed to determine whether strategies stayed the same on both short and long weeks (see Scheduling Practices), whether individuals generally slept more on days off than on work days, and if so, whether that was in preparation for their shifts ("banking" sleep), or to recover from them ("recovery" sleep).

\section{Adaptation Items}

A single item of self-reported adaptation to current work hours on a scale from 0 to 10 , previously utilized by Gamble \& colleagues, ${ }^{29}$ was included. Additionally, several SoS survey items were identified as reflecting a level of "adaptation" to shiftwork: 1) a measure of the degree to which shiftwork interferes with different domains (leisure, domestic, and non-domestic) on a 5-point scale (not at all [1] to very much [5]); 2) a Fatigue score, which is generated from 3 fatigue-related items; 3) two questions from the SoS Digestive subscale (appetite disruption and digestive difficulties); 4) a Sleep Difficulty Scale Score (from 5 to 25), calculated for each shift type worked in the last 6 months, as well as for days off; 5) a single item capturing the degree to which the respondent feels the advantages of shiftwork outweigh the disadvantages $(0=$ definitely not to $5=$ definitely yes), and 6) self-reported sleepiness in 2-h increments for the two major shift types. Sleepiness scale scores were subsequently binned into 3 categories (for day shift: Beginning $=6 \mathrm{am}, 8 \mathrm{am}, 10 \mathrm{am} ;$ Middle $=12 \mathrm{pm}$ and $2 \mathrm{pm}$; End $=4 \mathrm{pm}, 6 \mathrm{pm}, 8 \mathrm{pm}$; corresponding times 12 $\mathrm{h}$ later were used for night).

Two additional non-SoS measures of adaptation were included in the survey: an original item on the frequency of skipping meals on different shift types, and a fatigue and sleepiness-related driving incident measure, ${ }^{14}$ adapted to reflect incidents over the last week.

\section{Individual Characteristics}

Demographic survey variables were each examined alongside sleep strategies, including: age, gender, chronotype, marital status, number of dependents, shift type (rotating or permanent; $\%$ night work), commute length, sleep "flexibility," \% of schedule based on preference, and \% of time working night shifts.

It was hypothesized that questionnaire items about knowledge of the importance of sleep, circadian rhythms, and sleep-promoting behaviors might influence sleepscheduling strategies. It has been reported that physicians get approximately $2-3 \mathrm{~h}$ of sleep education during their medical training, ${ }^{43,44}$ but to our knowledge, exposure to sleep education has not yet been quantified in nurses outside of our studies. ${ }^{36}$ We therefore asked several investigator-developed questions regarding the extent of sleep knowledge, motivation to engage in healthy sleep behaviors, and exposure to education regarding sleep and circadian health.

A 5-item circadian and sleep knowledge scale and a 7-item motivation scale were used. Two items assessing the importance of sleep for health and for job performance were also included. A single item was added for education: As part of your professional training, how much education on sleep and/or circadian rhythms have you received? None whatsoever; a few hours or so (eg, one class); a full course; other. These items were added after data collection began and thus include only a subset of participants. 


\section{Analysis}

General

Analyses were performed in GraphPad Prism (La Jolla, Ca) and IBM SPSS Statistics 23.0 (IBM Corporation, Armonk, New York). For all correlations, missing data were excluded pairwise. Sample sizes are noted in Table legends. Unless otherwise specified, all statistical tests were evaluated at the $p<0.05$ alpha level.

\section{Adaptation/Disruption}

In examining adaptation by strategy, Pearson-product moment correlations between 5-point strategy frequency scale (0-4) and linear adaptation measures (self-reported adaptation (0-10), perceived advantages of/interference of shiftwork, gastrointestinal (GI) symptoms, fatigue, score, and sleep difficulty and skipping meals on different shift types) were calculated. For a more direct comparison to findings of Gamble and colleagues, self-reported adaptation was also binned in the same three categories ("not well" $(<4)$, "middle" (4-6), and "very well" $(\geq 7)$ ) and examined by strategy frequency using ANOVA. Typical sleepiness across the shift was examined via a mixed model with primary strategy type and binned time of day (beginning, middle, end) as fixed factors, and subjects as a random factor.

\section{Individual Characteristics}

Pearson-product moment correlations between 5-point strategy frequency scale (0-4) and motivation, knowledge, MEQ, years in shiftwork, and age were calculated. For categorical variables, such as gender, marital status, and dependents, frequency of employing any given strategy was binned into 3 categories to avoid small values and empty cells (frequently/most frequent, sometimes, and rarely/never), and Chi-square analyses were performed to determine relationships with strategy type and rationales. Responses in the 5-point rationale scale ( $1=$ not at all, $3=$ somewhat, $5=$ very much) were binned (1-2/3/4-5) for examination of strategy rationale by categorical demographic variables. As there were few endorsements of "other" as a rationale, that category was excluded from Chisquare analyses. In examining individual characteristics by most frequent single strategy employed, independent t-tests or ANOVAs were used, as appropriate.

\section{Results \\ Sleep-Scheduling Strategies and \\ Rationales \\ Day Shifts}

For day shifts, the Incomplete Shifter-D strategy was employed at the highest rate, followed by the Consistent and Napper strategies, while the Switch Sleeper-D was employed least often $(\mathrm{X} 2(6)=37.93 ; \mathrm{p}<0.001)$ (Figure 1A). Post-hoc tests further revealed the Incomplete Shifter-D strategy was employed at a higher rate than both the Napper $(p<0.05)$ and Switch Sleeper-D strategies $(p<$ $0.001)$, but not more than the Consistent strategy $(\mathrm{p}=0.11)$. Consistent and Napper strategies also occurred more than the Switch Sleeper (D) strategy $(\mathrm{p}<0.001$ and $\mathrm{p}<0.01$, respectively).

Most individuals used two or more strategies at least "sometimes" (63/75, 85\%), including 29 who did so "frequently" or more (39\%). However, amongst individuals for whom a primary sleep-scheduling strategy emerged $(\mathrm{n}=44)$, the Consistent strategy was most common when working day shifts $(n=15)$, followed closely by the Incomplete Shifter-D and the Napper strategies (both $\mathrm{n}=13$ ). Only 3 individuals endorsed Switch Sleeper-D as their primary strategy. The remaining individuals reported utilizing two or more sleep-scheduling strategies with equal frequency for day shifts.

Across the four categories of rationales for sleepscheduling strategy selection (leisure, domestic, nondomestic, and commute), there were differences in rationales $(X 2(6)=24.57(p<0.001)$, with domestic considerations being the most common (Figure 1C). Post-hoc tests revealed domestic concerns were significantly higher than nondomestic and commute (both $\mathrm{p}<0.001$ ), but not leisure $(\mathrm{p}=0.14)$. Leisure as a consideration was also higher than commute $(\mathrm{p}>0.05)$, but not non-domestic $(\mathrm{p}=0.06)$, and nondomestic and commute did not differ $(\mathrm{p}=0.32)$.

\section{Night Shifts}

There were two sleep-scheduling strategies that the largest number of individuals reported using "frequently" or as "the most frequent strategy" for night shifts: Switch Napper and No Sleep strategies (Figure 1B). Night Stay and Incomplete Shifter-N were the next most common, followed by Nap Proxy and Switch Sleeper-N strategies. Chi-square analysis of the three frequency categories (never/rarely, sometimes, and frequently/most frequent) 
A

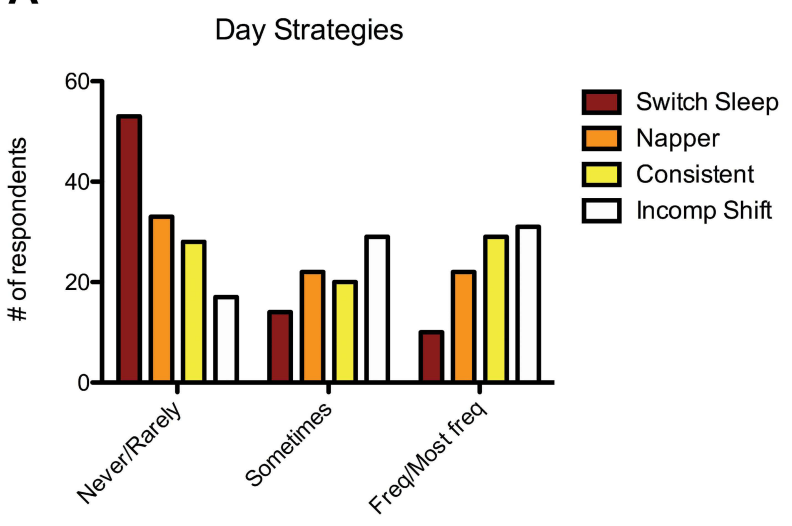

C

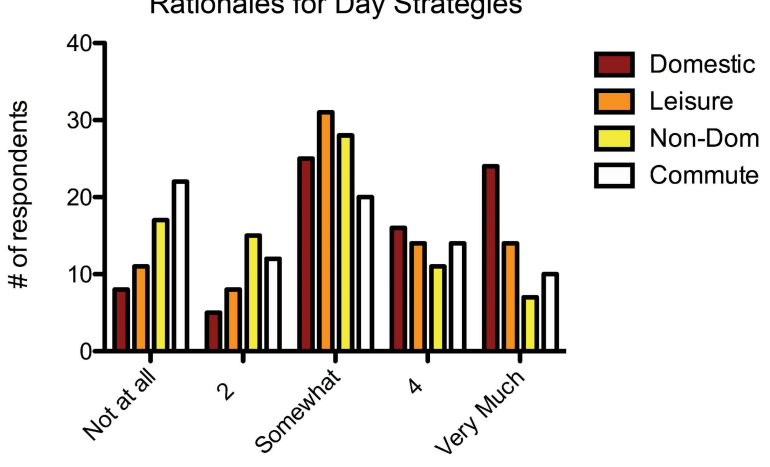

B

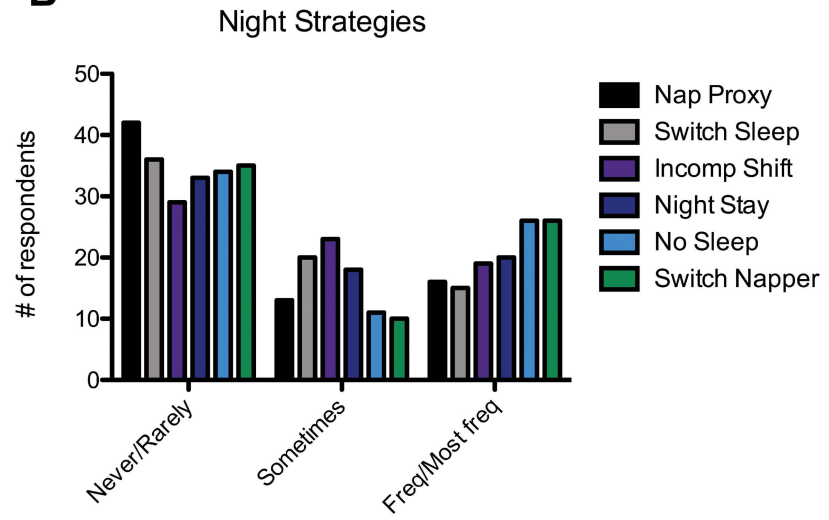

D

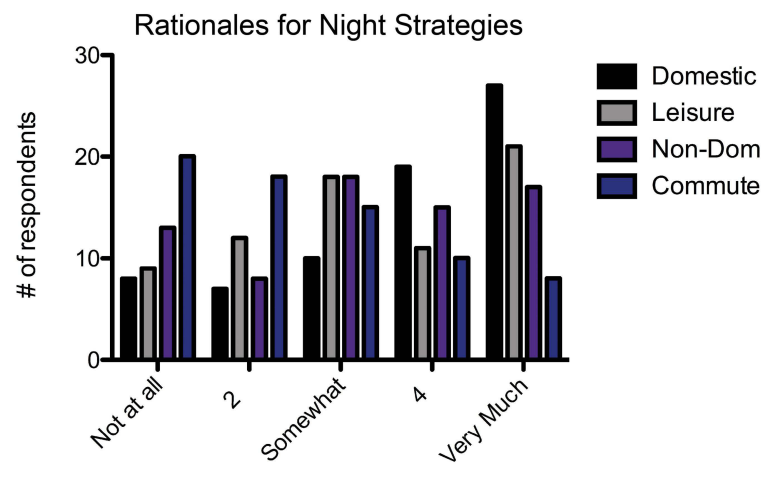

Figure I Frequency of employing specific sleep-scheduling strategies and rationales for strategies by shift type. The frequency of engaging in each sleep-scheduling strategy when working day (A) and night shifts (B). Participants reported frequency for each type on a scale of I-5, which was binned for chi-square analysis. Incomplete Shifter-D and Consistent were the most frequently used strategies for day shifts, and Switch Napper and No Sleep were for night shifts. Rationales for sleep-strategy selection included domestic, leisure, non-domestic concerns, as well as daily commute. Domestic concerns were the most frequently cited contributor to sleep-strategy selection for both day (C) and night shifts (D).

Abbreviations: Incomp Shift, Incomplete Shifter; Non-Dom, Non-Domestic; Freq, Frequently.

revealed no overall differences in strategy employment rates $(\mathrm{X} 2(12)=16.95 ; \mathrm{p}=0.08)$.

A majority reported utilizing two or more strategies at least some of the time (62/71, or $87 \%)$, and $36(51 \%)$ did so "frequently" for night shifts. Amongst individuals for whom a primary sleep-scheduling strategy emerged $(n=46)$, and consistent with the frequency ratings for the whole sample, individuals most frequently reported utilizing the No Sleep and Switch Napper strategies when working night shifts $(\mathrm{n}=12$ and 11, respectively). Those two strategies were followed by the Night Stay ( $\mathrm{n}=9)$, Incomplete Shifter-N ( $\mathrm{n}=6)$, Nap Proxy ( $\mathrm{n}=5)$, and Switch Sleeper-N ( $\mathrm{n}=3$ ) strategies.

Rationales for night shifts were similar to those for days, with the domestic rationale being the most common (X2(6) $=24.57(\mathrm{p}<0.001)$ (Figure 1D). Leisure and non-domestic reasons were endorsed with equal frequency. Post-hoc tests revealed domestic concerns were higher than commute $(\mathrm{p}<$ 0.001), with commute also being lower than both leisure and non-domestic concerns (both $\mathrm{p}<0.05$ ).

\section{Rotating Shifts}

Participants were instructed to complete items for the shift type(s) they had worked in the last 6 months. Most individuals reported strategies for both day and night $(n=61)$. In those participants, adopting a Consistent strategy for day shifts was related to doing the same for night shifts ("Night Stay" strategy; $r=0.27, p<0.05$ ), and negatively related to napping on day shifts $(\mathrm{r}=-0.22, \mathrm{p}=0.05)$. Adopting Switch Sleeper for days was also associated with that same strategy for nights $(\mathrm{r}=0.43, \mathrm{p}<0.01)$. Additionally, the Napper strategy for Day shifts was associated with the two napping strategies for night shifts: $\mathrm{r}=0.27, \mathrm{p}<0.05$ for Switch Napper and $r=0.40, p<0.01$ for Nap Proxy. There was a trend for a relationship between Night Stay and Switch Sleeping strategy for Day shifts $(\mathrm{p}=0.07)$. There was no relationship between Incomplete Shifter for the two shift types $(p=0.11)$, nor for any other combination of strategies across day and night shifts (all others, $p>0.21$ ). 
Rotating shiftworkers were more likely than permanent day workers to adopt the "Napper" strategy for day-shifts (X2[12] 18.89, $\mathrm{p}<0.01$; all others, $\mathrm{p}>0.27$ ). Considerations behind strategy selection were not different between the two groups of workers (all $p>0.34$ ). No differences by job-type were found for either night-shift sleep strategy frequency (all $p>0.36$ ) or life domain influence on night-shift sleep strategy selection (all $p>0.18$ ) (see Supplementary Materials for more information).

\section{Shiftwork Adaptation/Disruption}

There were differences in the amount of adaptation (0-10) reported by type of shiftwork $(\mathrm{X} 2(4)=10.68 ; \mathrm{p}<0.05)$ (Figure 2). Of note, only $23 \%$ of all staff reported being well-adjusted (scored $\geq 7$ ) by this measure, in general. Within each shift type, $53 \%$ of permanent day workers reported being well adapted, as compared to only $17 \%$ and $23 \%$ of rotating and permanent night workers, respectively. Post hoc tests revealed rotating shiftworkers reported worse adaption overall than permanent day workers $(\mathrm{X} 2(2)=9.25$; $\mathrm{p}<0.01$ ); permanent night workers did not differ from either group, though sample sizes of day and night groups were relatively small ( $\mathrm{n}=15$ and 13 , respectively).

Measures of adaptation were generally correlated with one another (Table S1), and associations with frequency of using each strategy are shown in Table 3. Sleep strategy frequency did not vary across levels of adaptation (Not well, Middle, Very Well) for any single strategy (Table

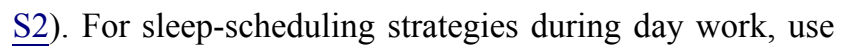
of the Incomplete Shifter-D strategy was associated with GI symptoms, while use of the Consistent strategy was negatively associated with GI symptoms (Table 3).

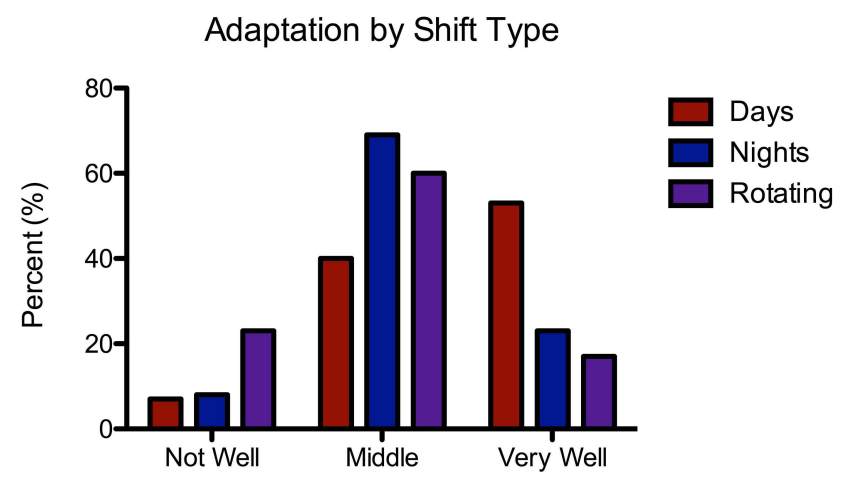

Figure 2 Adaptation by shift type. Adaptation for permanent day workers, permanent night workers, and workers who rotated from day to night was reported on a scale from 0 to 10 and binned into three categories as in Petrov et al, 20I4: Not well, Middle, and Very well.
For sleep-scheduling strategies during night work, frequency of engaging in the Switch Napper strategy was positively associated with higher self-reported adaptation to shiftwork (Table 3). Use of the Incomplete Shifter-N strategy was associated with perceived interference of shiftwork in all three life domains (domestic, non-domestic, and leisure), and also with reported GI symptoms and skipping one or more meals on the night shift. Frequency of engaging in the Switch Sleeper-N strategy was also associated with skipping meals on the night shift. Adopting a higher number of strategies at least "frequently" was positively related to skipping meals on the night shift $(\mathrm{r}=0.32, \mathrm{p}<0.01)$, and negatively related to selfreported adaptation $(\mathrm{r}=-0.25, \mathrm{p}<0.05)$. Though no strategies were related to driving incidents, a full $79 \%$ percent of our sample reported having a driving incident of some kind in the last week.

\section{Sleepiness on Shift}

In those with a primary sleep strategy ( $\mathrm{n}=44$ for day, $\mathrm{n}=46$ for night), sleepiness on shift was analyzed across time on shift (Beginning/Middle/End) and primary strategy type. A main effect of time-on-shift was found in reported sleepiness on day shifts $(\mathrm{p}<0.001$; Figure 3$)$, with lower sleepiness mid-shift relative to beginning and end (both $p<0.01$ ), but no main effect or interaction for primary strategy (both $p>0.58$ ). For sleep-scheduling strategies on night shifts, a main effect of time-on-shift $(\mathrm{p}<0.001)$ and a significant interaction of timeon-shift and sleep-scheduling strategy was observed $(\mathrm{p}<$ $0.05)$, with no main effect of sleep strategy $(\mathrm{p}=0.38)$. Posthoc tests indicate that sleepiness mid-shift was higher for Switch Napper than for Night Stay, Switch Sleeper-N, and Nap Proxy (all $p<0.05$ ). Across all strategies, sleepiness grew across the shift, with more sleepiness in the middle than at the beginning, and more sleepiness at the end than the middle (both $\mathrm{p}<0.001$ ). In terms of correlations, frequency of engaging in Switch Sleeper-N and Night Stay strategies was negatively correlated with sleepiness mid-shift $(r=-0.25, \mathrm{p}<0.05$ and $\mathrm{r}=0.33, \mathrm{p}<0.01$, respectively). There were no relationships between sleepiness across the shift on day shifts and day shift sleep-scheduling strategies (all $\mathrm{p}>0.16$ ).

\section{Relationships with Individual Characteristics}

Relationships between continuous demographic variables, strategy frequency, and rationales are shown in Table S3. For the sake of brevity, only statistically significant results are reported below (see Table S3 for full results). For night 


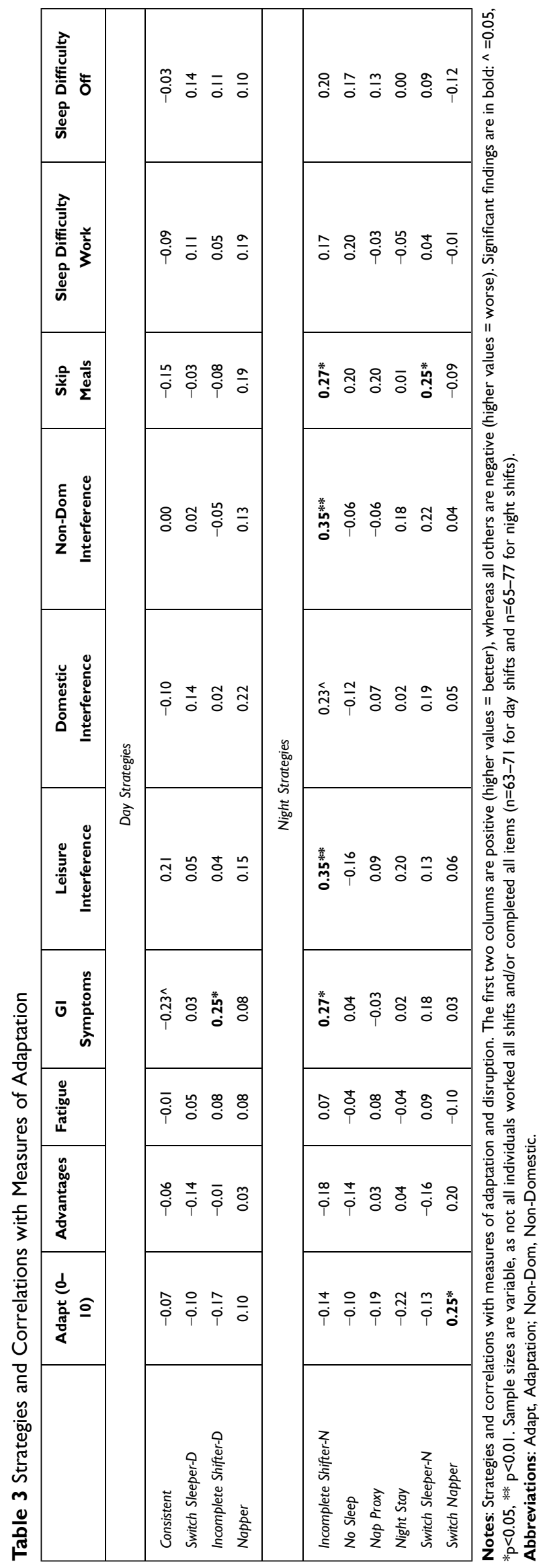

shifts, several characteristics were associated with adoption of a napping strategy: 1) morningness was negatively associated with frequency of engaging in the Nap Proxy sleep strategy, and 2) having higher sleep "flexibility" on the SoS scale was associated with more frequent adoption of the Switch Napper strategy. A few job characteristics were associated with strategy selection. The higher percentage of time individuals spent working nights, the less likely they were to adopt either the Incomplete Shifter-N strategy, or the Consistent strategy for day shifts $(\mathrm{r}=-0.27$, $\mathrm{p}<0.05)$. Further, having less of one's schedule based on preference was associated with use of the Incomplete Shifter-N strategy, as well as with endorsing leisure as a rationale for night strategies. Finally, longer commute times (both to and from work) were associated with adoption of the Switch Napper strategy and, as might be expected, greater endorsement of their commute as a rationale for sleep-scheduling strategy selection on both days and nights.

In terms of discrete variables, individuals with one or more children in the home were more likely to use the Napper strategy occasionally when working days, whereas responses from those without children were more polarized ("never" or "frequently"; X2(4)=13.12, p < 0.05). These results are similar when "any" dependent is included. Individuals with any dependent were also more likely to indicate that domestic life plays a part in the selection of their sleep-scheduling strategy on day shifts $(\mathrm{X} 2(4)=11.36, \mathrm{p}<0.05)$, but other considerations do not (all $\mathrm{p}>0.09$ ). Similarly, those who were married or cohabitating were more likely to cite domestic reasons for sleep-scheduling strategies for day shifts $(p<0.05$; all other $\mathrm{p}>0.09$ ). See Supplementary Materials for comparisons by job title.

With regard to education on sleep and circadian rhythms, the majority of participants reported receiving "None whatsoever" ( $\mathrm{n}=53 / 87 ; 60.9 \%)$; another 32 (36.8\%) reported receiving "A few hours or so (eg, one class)". Preliminary data from a subset $(n=19)$ of these individuals were recently reported, ${ }^{36}$ and those findings were consistent with the results of the broader sample reported here. A subset of participants $(n=58)$ received additional questions regarding motivation to engage in healthy sleep behaviors and general knowledge on sleep and circadian principles. Participants on average answered $49.0 \%$ of the questions on sleep and circadian knowledge correctly. In spite of this, average sleep motivation scores were $4.23 \pm 0.71$ on a scale from 1 to $5(\operatorname{mean} \pm \mathrm{SD})$, and all 

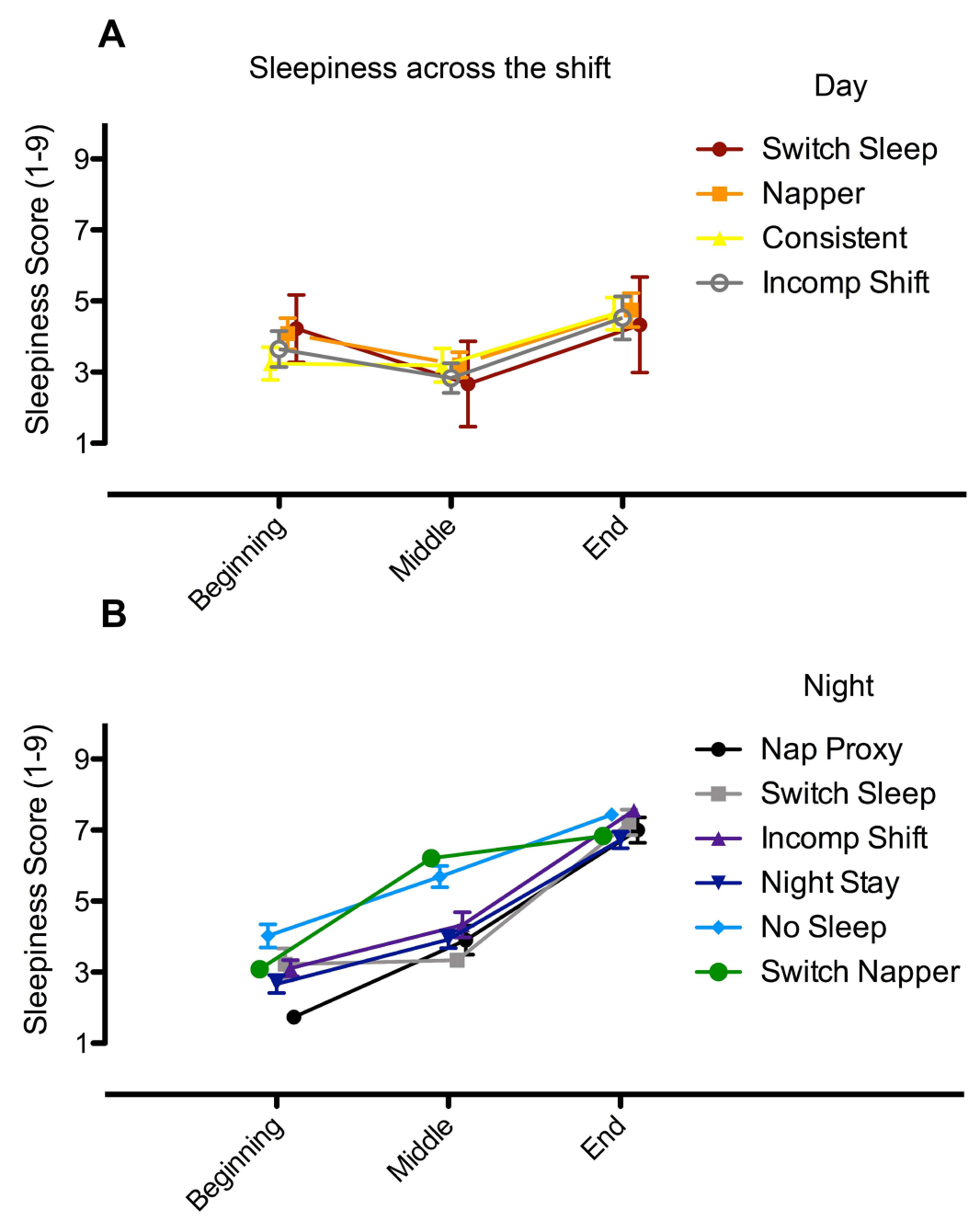

Figure 3 Sleepiness across the shift by primary sleep-scheduling strategy. Retrospectively reported sleepiness scores on a scale of I-9 across $12 \mathrm{~h}$ day (A) and night shifts (B), binned into beginning, middle, and end of shift (mean \pm SEM). Symbols are offset slightly on the X-axis for ease of viewing. Error bars are present, but in some cases are obscured by symbols.

Abbreviations: Incomp Shift, Incomplete Shifter

participants rated sleep at least "moderately important" for both job performance and health, with the majority endorsing it as "extremely important" $(\mathrm{n}=34$ for performance $(58.6 \%) ; \mathrm{n}=37$ for health $(63.8 \%))$.

Motivation to engage in healthy sleep behaviors was negatively associated with adoption of the No Sleep strategy on night-shifts (Table S3). Sleep and circadian knowledge was negatively correlated with use of the Incomplete Shifter-D strategy (Table S3), as well as the number of strategies adopted at least sometimes for day shifts $(r=-0.30, p<0.05)$. Independent $t$-tests of the two most common responses to sleep education/training ("None whatsoever" $(\mathrm{n}=53)$ and "A few hours or so (eg, one class)" $(\mathrm{n}=32))$ revealed that those with no sleep education whatsoever reported engaging in the
No Sleep strategy for night shifts more frequently than those with some education $(\mathrm{t}=5.25(66), \mathrm{p}<0.05)$. There was a trend for those with some education to engage more frequently in the Napper strategy for day shifts, as well $(t=3.38(66) ; p=0.07)$. There were no other effects of sleep education on strategy selection (all $\mathrm{p}>0.19$ ).

\section{Additional Sleep-Scheduling Information}

Most individuals reported utilizing the same strategies for short and long weeks for both days (74/78) and nights (65/ 70). Comments regarding differences between long and short weeks on day shifts included individuals napping more on long weeks $(n=2)$. For nights, comments included references to attempting to "adjust" more on long weeks and just "power through" (sleep less) on shorter weeks or 
single night shifts ( $\mathrm{n}=3)$. A majority of individuals $(79 / 88$, or $89 \%$ ) reported sleeping more on their days off than on work days. Of those, 36 (46\%) reported doing so to recover from sleep loss, 3 (4\%) reported doing so to prepare for sleep loss ("banking"), and 40 (51\%) reported doing so for both reasons (recovery and banking).

Responses to open-ended questions were screened to determine whether individuals had additional strategies, and also to determine whether or not individuals comprehended strategy definitions and the distinctions between them. In general, there were few comments made $(n=17)$. Several hinted at conditional circumstances for strategy use, such as needing to take a child to an event $(n=5)$, while others provided clarification on combinations of strategies used $(n=3)$. Both of these indicate the use of multiple strategies by the same individual. Very few comments seemed to fit into existing strategy options $(n=4)$, indicating the categories were not generally misunderstood, and that they captured well the strategies employed by this group. One individual made comments regarding rationales and general sleep difficulty that provided no new information on strategies. A final potential strategy reported $(n=4)$ that may warrant additional consideration in subsequent research is polyphasic sleep (distinct from the biphasic Napper and Nap Proxy strategies), though there were associated comments indicating that the sleep patterns were due to sleep difficulty rather than intention to sleep in multiple bouts.

\section{Discussion}

The Incomplete Shifter-D was the most frequently employed strategy for day shifts, and the No Sleep and Switch Napper were the two most frequent for nights. Importantly, a vast majority of individuals (>85\%) reported using multiple sleep-scheduling strategies, at least sometimes, on each of the two shift types studied here, a novel finding worth considering in future studies of sleep-scheduling strategies. While the relatively long period of reporting (over the past 6 months) may have resulted in a wider variety of strategies per person than smaller time periods (eg, one month), we observed no general pattern of strategy changes from week to week ("long" vs "short" work weeks). The observed relationship between lower adaption and utilization of more strategies supports the theory that being less consistent with sleepscheduling strategy is not adaptive; however, it may also reflect attempts to try a variety of strategies in the face of feeling poorly adapted. These competing theories, although difficult to tease out in this sample, might be explicitly tested in future work.

Though our smaller sample size of permanent workers somewhat limits our ability to evaluate any differences between them and rotating workers, those working rotating schedules reported less adaptation overall, and were also more likely to nap on day shifts than permanent workers (Figure 2). This may reflect the fact that working day shifts requires a period of circadian adjustment for rotating workers, at least at the beginning of a 6-week rotation. Additionally, rotating workers that adopted one napping strategy tended to adopt other napping strategies, consistent with the concept of "nappers" and "non-nappers" in the general population, ${ }^{15}$ as well as the concept of sleep flexibility as an adaptive characteristic in shiftwork. In our sample, having more sleep "flexibility" was associated with more frequent adoption of the Switch Napper strategy on night shifts, a strategy that necessarily involves sleeping at different times from one day to the next. We also found flexibility in sleeping habits related to better adaptation, consistent with findings from others that flexible sleepers are better-adapted ${ }^{45}$ and get better daytime sleep. ${ }^{24}$ As in the general population, there may be some cultural and/or personal barriers to napping that might be addressed with increased education on sleep and circadian rhythms in shiftworkers.

We predicted that the strategies with the least amount of circadian disruption and/or sleep deprivation would likely relate to measures of better self-reported adaptation. The strategies most consistent in terms of sleep timing and/or circadian phase are the Consistent and Napper strategies for Day shifts, and the Night Stay for night shifts, with the important caveat that research suggests that even night shiftworkers who maintain a nocturnal phase position on days off do not adjust physiologically to night shifts due to exposure to bright light when coming off-shift. ${ }^{2,3}$ Night Stay was found to be most adaptive in previous work of night-shift strategies, though small sample sizes prevented it from being analyzed as comprehensively as other strategies. ${ }^{29}$ As discussed above, the Incomplete Shifter-D strategy is likely the least adaptive strategy for day shifts in that it has the most variable sleep timing, and indeed, it was associated with more GI symptomology. For night, the strategies of No Sleep and Switch Napper both offer the least amount of sleep on the first night in a series of night shifts, and also necessarily mean the individual has some day-to-day variability in sleep 
timing, and are thus likely the least adaptive in terms of sleep duration and regularity.

On-shift sleepiness was worse for those primarily adopting the Switch Napper strategy relative to those adopting primarily Night Stay, Switch Sleeper-N, and Nap Proxy strategies. Paradoxically, however, frequency of adopting the Switch Napper strategy was related to higher levels of self-reported adaptation. This type of contradiction has been reported in some comparisons of subjective sleepiness to other measures of performance, ${ }^{46,47}$ and is also not uncommon in shiftwork studies - certain strategies, interventions, or countermeasures that may be beneficial for some aspects of health and performance, like alertness on shift, may result in other negative effects, like impaired sleep or reduced time with family. This highlights tradeoffs commonly observed for work- and sleep-scheduling choices in shiftworkers. It also indicates that perhaps a more nuanced approach to measuring adaptation in shiftwork is appropriate, rather than a single outcome measure. The SoS in fact does include multiple domains intended to describe "tolerance to shiftwork" for this reason, most of which were related in our sample (see Table S1).

A full $50 \%$ of the individuals for whom a primary sleep-scheduling strategy emerged for night shifts relied on sleep restriction (Switch Napper) or total deprivation (No Sleep) for the first night in a series. In the previous body of work ${ }^{29,30}$ Switch Sleeper-N was the most common strategy (over $50 \%$ ), followed by No Sleep $(\sim 20 \%)$. This difference, paired with the fact that Switch Sleeper-N was least common in our sample, likely reflects our inclusion of the Switch Napper strategy, which was subsumed by the "Switch Sleeper" category in prior work, but is a distinct strategy in ours. Other potential explanations include our use of frequency ratings rather than a single strategy for each individual and/or our use of self-ascribed, explicit strategies vs categorization of predicted sleep schedules into strategy types by investigators. Of note, one recent study of shiftworkers utilizing sleep-scheduling predictions against real-time diary data found that individuals tended to sleep later than predicted. ${ }^{7}$ These differences also suggest that in addition to methodological factors, institutional, departmental, and population characteristics may affect strategy selection in ways that are not yet fully understood. It is important then, that any sleep-scheduling strategy study make note of or even account for such factors, by increasing sample size to do so, when possible.
It is quite alarming how commonly sleep restriction (Switch Napper), sleep deprivation (No Sleep), and biphasic sleep (Nap Proxy) emerged as primary strategies, together accounting for $61 \%$ of the sample. Based on anecdotal information, it appears that shiftworkers often employ the No Sleep strategy to increase homeostatic sleep drive such that the pressure to sleep is strong enough to allow the individual to sleep during the day after the first night shift, at the "wrong" circadian time. In terms of sleepiness, while those adopting the Switch Napper and No Sleep strategies were the highest, and while power was limited due to small sample size in some groups, shiftworkers in all primary strategy types were above or near 7 , a score considered to be a safety threshold. ${ }^{48,49}$ Importantly, this is their level of sleepiness just before the commute home, and a majority of individuals reported having a driving incident in the past week. Institutions should consider minimizing extra work and other administrative tasks post-night shift, especially on the first night in a series.

The Switch Napper may be used as a way of reducing the perception of misalignment during transitions to night work (introducing daytime sleep before the first shift, while maintaining old circadian phase). While getting a nap in before the first night shift is certainly recommended by experts relative to staying up for $>24$ $\mathrm{h}$ straight (No Sleep), the benefits of the nap simply cannot be sufficient enough to entirely do away with the homeostatic sleep pressure that would build up from waking from the last, long sleep so many hours before the shift began. Also, in spite of getting inadequate sleep, individuals in this sample did not explicitly report "banking" sleep per se, although almost half reported using sleep both to recover and prepare for sleep deprivation during work days. We did find that participants were highly motivated and believed sleep to be important for health and performance. Again, educational interventions may be helpful in prioritization of sleep-scheduling strategies. Additionally, motivation was associated with the degree to which schedules were based on preference; thus, shiftworkers with no schedule control may feel helpless and give up trying to get better sleep. Conversely, those who prioritize control of their schedule may make different career choices (eg, compromise on pay for autonomy). Interventions that allow workers to have some control over their schedules might also improve motivation to prioritize sleep and lead to better sleep scheduling strategy choices. Educational interventions with suggestions for specific strategies 
could help improve motivation as well, thereby improving sleep indirectly.

In previous work, the strategies categorized as "most adaptive" for night shifts were the Incomplete Shifter-N and the Switch Sleeper-N, both of which necessarily get more sleep than the No Sleep and Nap Proxy, but also involve reduced regularity in sleep timing. In that study, our novel strategy, Switch Napper, was subsumed under Switch Sleeper. With the current study, very few participants endorsed Switch Sleeper while many more endorsed Switch Napper. This indicates that more nuanced categorization of strategies might be in order. Importantly, the Incomplete Shifter-N strategy has been likened to the compromise phase position, ${ }^{30}$ a circadian strategy for minimizing disruption when working nights by aligning the sleep phase on days off such that half of it occurs during the time sleep would occur on day shifts, and half when the individual would be sleeping on night shifts (eg, sleeping from $4 \mathrm{am}-12 \mathrm{pm}) .{ }^{50}$ Here, the Incomplete Shifter$\mathrm{N}$ strategy was related to numerous negative outcomes in terms of adaptation, including GI distress, sleep difficulty, and perceived interference in all three life domains. However, the compromise phase position theory actually depends a great deal on a lighting regime of minimizing and maximizing exposure at very specific times of day. Thus, while they may appear similar on the face of it, keeping circadian phase aligned would be unlikely under the Incomplete Shifter-N strategy without the lighting regime as an adjunct. ${ }^{50}$

Evidence suggests polyphasic sleep is common in shiftworkers. ${ }^{26,27}$ Here, we find supporting evidence that napping on day shift is relatively common, as is adoption of the two strategies for night shifts that involve napping, either regularly (Nap Proxy) or before the first night shift only (Switch Napper). Independent of the benefits of napping from a sleep homeostat perspective, as well as limited evidence that polyphasic sleep can be as good as a single bout of sleep by some measures, ${ }^{51-54}$ it has been theorized that a bifurcated waveform might be advantageous for shiftworkers; ${ }^{55,56}$ however, as in the case of the compromise phase position, this would be the case only if the underlying pacemaker truly adapted to the light schedule. Such a feat would be difficult to achieve outside of laboratory settings, and would require the use of blue-blocking glasses, scheduled natural light, and other aids for light modulation. Regardless of sleep-scheduling strategy, any sleep education program in shiftworkers should include the optimization of timed light exposure. Further, volitional polyphasic sleep as a sleep-scheduling strategy must be considered distinct from polyphasic sleep as a result of sleep disruption, such as that reported by some participants in this study.

Importantly, many of our findings were for those working day shifts, a relatively understudied group of shiftworkers generally, ${ }^{5,6,9}$ that nevertheless suffer due to early start times and/or long shifts. Furthermore, rotating workers adopted different strategies on day shifts than permanent day workers, suggesting more research should be done to examine sleep-scheduling strategies in all of these subpopulations.

While past investigators looked at correlates of individual characteristics and strategy, we added explicit items examining the rationale for strategy use in order to begin assessing how modifiable sleep strategies might be. While domestic considerations were generally the most common rationale for sleep-scheduling strategies for both day and night, those with children, dependents, and live-in partners were even more likely to endorse domestic considerations. An intervention study wherein shiftworkers could schedule their own shifts ${ }^{57}$ revealed a somewhat similar pattern, in that leisure and family time were prioritized over sleep and rest, and individuals with children placed leisure as a lower priority than those without. Interestingly, those who more frequently employed the Switch Napper strategy were more likely to indicate commute played a part in strategy choice, as were individuals with longer commutes on both shift types.

We also hypothesized that individual characteristics may influence sleep-scheduling strategy selection. For example, age, gender, chronotype, and flexibility have been related to shiftwork adaptation, ${ }^{24,35}$ and caregivers have reported prioritizing family, sleep, etc. when making their own work schedules, ${ }^{57}$ which might also affect sleep strategy selection. We found differences in sleepscheduling strategies by chronotype, sleep flexibility, rotating status, job title, dependents, $\%$ working night shifts, $\%$ schedule based on preference, and level of sleep education, with no differences by age, gender, marital status, or sleeprelated knowledge. One might expect that any differences in sleep-scheduling strategy by chronotype might also apply based on age; however, age and chronotype were unexpectedly not associated in our sample (see Supplementary Materials). This might reflect the unique sample, as participants in this study were mostly activeduty military, a relatively understudied group of individuals with regard to chronotype. ${ }^{58,59}$ 
Later chronotypes were also more likely to adopt a Nap Proxy strategy for night shifts, whereas previous studies indicate a link between eveningness and the Incomplete Shifter-N and Switch Sleeper-N strategies ${ }^{29,30}$ (though there was a trend for a relationship between eveningness and Incomplete Shifter-N frequency in our sample). Evidence of the influence of chronotype on napping in shiftworkers has been somewhat mixed, ${ }^{60,61}$ as have the interactions between chronotype and adaptation to shiftwork. .,29,30,62 Our sample tended to skew towards morningness (Table 1), a relatively uncommon distribution in shiftworkers, which might reflect, in part, the early rise times in the population, ${ }^{59}$ and may also account for some differences between our findings and those of previous work. Other methodological differences may also contribute, including different chronotype and strategy measures, as well as demographic differences, including our use of a slightly younger, more diverse, and predominantly rotating shiftwork sample.

Sleep-scheduling strategies did differ by whether individuals had children or other dependents in the home, but only for day shifts. Individuals with one or more dependents in the home were more likely to use the Napper strategy occasionally relative to those without, rather than often or never, which may reflect a more opportunistic approach to napping that is affected by what else is happening in the home. Those who worked nights more often were less likely to use the Consistent strategy for day shifts and the Incomplete Shifter-N for night shifts, while those who had greater control over their schedule were more likely to use the Incomplete Shifter-N.

Of note, general education of health-care providers in sleep and circadian rhythms was quite low, with most individuals reporting having received "none whatsoever." Given the importance of sleep for health, this is far from ideal. Similarly, low rates of education in sleep and circadian rhythms have been reported in physicians as well, and have resulted in efforts to develop educational programs to address the issue. ${ }^{43}$ As predicted, strategies that resulted in sleep loss were less frequently utilized by those with relatively more education on circadian rhythms and sleep as well as more motivation to change sleep behavior. General education level in shiftworkers has been associated with the belief that rest is important, ${ }^{57}$ and educational interventions for shiftworkers typically result in improved outcomes. ${ }^{63}$ In our sample, those with more sleep education, motivation, and/or knowledge were less likely to engage in the Incomplete Shifter-D and the No
Sleep strategy for days and nights, respectively. Compared to the other 3 strategies for day shifts, the Incomplete Shifter-D inherently has more day-to-day variability in the timing of sleep, which has recently been related to impairments in long-term cognitive performance outcomes, in part as a result of the repeated "social jetlag" it causes. ${ }^{19,20}$ It is unclear why the results from the general sleep measure and the specific knowledge question are not consistent (ie, point to the use of different strategies); one explanation may be that the material covered in single courses of sleep education may have more to do with sleep disorders (eg, restless legs, apnea) than with circadian rhythms and sleep per se.

Strengths of this study include several novel aspects, such as characterization of multiple strategies in the same workers; examination of strategies for day workers, who are understudied yet are affected by early rise times; and an examination of factors that influence sleep scheduling strategy selection. Additionally, much of the data are withinsubjects across multiple shift types. Limitations of the study include that it is based on retrospective self-report, and that while we explicitly asked about volitional sleep strategies, we may also be capturing sleep patterns that happen without formal intention or forethought. Future work should examine these strategy measures alongside objective measures, as well as attempt to tease out intentional strategies from more passive/random sleep patterns.

\section{Conclusion}

Shiftworkers, both day and night (and rotating, the most), are particularly at risk for sleep disruption as well as other physical and psychological health issues. The shiftworkers here reported significant disruption from their schedules, but believed sleep to be important for performance and health, and were highly motivated to improve sleep. Given the relationship between sleep-related education and sleepscheduling strategy selection, this population would likely benefit from educational interventions regarding circadian rhythms and sleep. Furthermore, shiftworkers early on in their careers in hierarchical systems, such as medicine, can be disproportionally adversely affected by shiftwork scheduling practices, and in this current sample, the greater scheduling choice was indeed related to years in shiftwork. Additionally, the benefits of countermeasures that may be employed when an individual cannot change their schedule should be emphasized for shiftworking populations, in general. In particular, more research should focus on the timing, duration, and regularity of sleep patterns and sleep- 
scheduling strategies in real-world settings. For example, an explicit study of the cognitive benefits of banking sleep vs keeping a consistent schedule should be examined, as should studies of polyphasic sleep in shiftworkers. Where possible, large sample sizes and objective measures should also be employed. That individuals adapt multiple strategies, for a variety of reasons, should also be addressed.

\section{Acknowledgments}

The authors gratefully acknowledge funding support from the TriService Nursing Research Program under Grant No. N16-503. The authors would also like to thank the nurses, corpsmen, and staff at NMCSD who contributed their time to this effort.

\section{Author Information}

The views expressed in this article reflect the results of research conducted by the authors and do not necessarily reflect the official policy or position of the Department of the Navy, Department of Defense, nor the United States Government. AY is a military service member, and GG is a civilian employee of the United States government. This work was prepared as part of their official duties. Title 17 U.S C. 105 provides that "copyright protection under this title is not available for any work of the United States government." Title 17 U.S.C. 101 defines a US Government work as work prepared by a military service member or employee of the US Government as part of that person's official duties.

\section{Disclosure}

Dr Gena Glickman reports grants from Office of Naval Research, grants from Department of Energy, grants from TriService Nursing Research Program, grants from Congressionally Directed Medical Research Program, during the conduct of the study; non-financial support from BIOS Lighting, non-financial support from f-lux, travel support from PennWell, LightShow West, and Well Building Institute, personal fees from Progressive Lighting and Radiometrics, outside the submitted work; In addition, Dr Gena Glickman has a patent 10213619 B2 licensed to Litebook, a patent 10603507 licensed to Litebook, a patent 7678140 B2 licensed to Litebook, a patent 8366755 B2 licensed to Litebook, a patent 16/657927 licensed to Litebook, a patent 16/831737 licensed to Litebook; Dr Gena Glickman and Dr Elizabeth Harrison have an educational program, Circadian Light and Sleep Skills (CLASS), that aims to provide knowledge, motivation and concrete tips for improving sleep and circadian health, which has been developed and is currently under study.

The authors report no other conflicts of interest in this work.

\section{References}

1. Evans JA, Davidson AJ. Health consequences of circadian disruption in humans and animal models. Prog Mol Biol Transl Sci. 2013;119:283-323.

2. Smith MR, Eastman CI. Shift work: health, performance and safety problems, traditional countermeasures, and innovative management strategies to reduce circadian misalignment. Nat Sci Sleep. 2012;4:111-132.

3. Folkard S. Do permanent night workers show circadian adjustment? A review based on the endogenous melatonin rhythm. Chronobiol Int. 2008;25(2-3):215-224. doi:10.1080/07420520802106835

4. Åkerstedt T. Shift work and disturbed sleep/wakefulness. Occup Med (Chic Ill). 2003;53(2):89-94. doi:10.1093/occmed/kqg046

5. Kecklund G, Akerstedt T. Effects of timing of shifts on sleepiness and sleep duration. J Sleep Res. 1995;4:47-50. doi:10.1111/j.13652869.1995.tb00226.x

6. Ganesan S, Magee M, Stone JE, et al. The impact of shift work on sleep, alertness and performance in healthcare workers. Sci Rep. 2019;9(1):1-13. doi:10.1038/s41598-019-40914-x

7. Harrison EM, Walbeek TJ, Maggio DG, Herring AA, Gorman MR Circadian profile of an emergency medicine department: scheduling practices and their effects on sleep and performance. J Emerg Med. 2020;58(1):130-140. doi:10.1016/j.jemermed.2019.10.007

8. Knauth P. Strategies for the implementation of new shift systems. J Hum Ergo. 2001;30:9-14.

9. Harrison EM, Schmied EA, Yablonsky AM, Glickman GL. Implementation of interventions designed to enhance the circadian health of shiftworkers. Chronobiol Int. 2021;38(4):467-479. doi:10.1080/07420528.2020.1845190

10. Guilleminault C, Powell NB, Martinez S, et al. Preliminary observations on the effects of sleep time in a sleep restriction paradigm. Sleep Med. 2003;4(3):177-184. doi:10.1016/S1389-9457(03)00061-3

11. Dijk DJ, Czeisler CA. Contribution of the circadian pacemaker and the sleep homeostat to sleep propensity, sleep structure, electroencephalographic slow waves, and sleep spindle activity in humans. $J \quad$ Neurosci. 1995;15(5 Pt 1):3526-3538. doi:10.1523/ JNEUROSCI.15-05-03526.1995

12. Smith SS, Kilby S, Jorgenson G, Douglas JA. Napping and nightshift work: effects of a short nap on psychomotor vigilance and subjective sleepiness in health workers. Sleep Biol Rhythms. 2007;5(2):117-125. doi:10.1111/j.1479-8425.2007.00261.x

13. Åkerstedt T, Peters B, Anund A, Kecklund G. Impaired alertness and performance driving home from the night shift: a driving simulator study. J Sleep Res. 2005;14(1):17-20. doi:10.1111/j.1365-2869.20 04.00437.x

14. Ftouni S, Sletten TL, Howard M, et al. Objective and subjective measures of sleepiness, and their associations with on-road driving events in shift workers. J Sleep Res. 2013;22(1):58-69. doi:10.1111/ j.1365-2869.2012.01038.x

15. Milner CE, Cote KA. Benefits of napping in healthy adults: impact of nap length, time of day, age, and experience with napping. J Sleep Res. 2009;18(2):272-281. doi:10.1111/j.1365-2869.2008.00718.x

16. Rupp TL, Wesensten NJ, Bliese PD, Balkin TJ. Banking sleep: realization of benefits during subsequent sleep restriction and recovery. Sleep. 2009;32(3):311-321. doi:10.1093/sleep/32.3.311 
17. Patterson PD, Ghen JD, Antoon SF, et al. Does evidence support "banking/extending sleep" by shift workers to mitigate fatigue, and/ or to improve health, safety, or performance? A systematic review. Sleep Health. 2019;5(4):359-369. doi:10.1016/j.sleh.2019.03.001

18. Zarcone VP. Sleep hygiene. In: Kryger MH, Roth T, editors. Principles and Practice of Sleep Medicine. Elsevier. 1994:542-548.

19. Smarr BL. Digital sleep logs reveal potential impacts of modern temporal structure on class performance in different chronotypes. J Biol Rhythms. 2015;30(1):61-67. doi:10.1177/0748730414565665

20. Phillips AJK, Clerx WM, O’Brien CS, et al. Irregular sleep/wake patterns are associated with poorer academic performance and delayed circadian and sleep/wake timing. Sci Rep. 2017;7(1):1-3. doi:10.1038/s41598-017-03171-4

21. Tepas DI. Shiftworker sleep strategies. J Hum Ergol. 1982;11:325-336. doi:10.11183/jhe1972.11.Supplement_325

22. Henderson NJ, Burt CDB. An evaluation of the effectiveness of shift work preparation strategies. NZ J Psychol. 1998:27(1):13.

23. Ruggiero JS, Sleep A-IT. Patterns of emergency department nurses on workdays and days off. J Nurs Res. 2016;24(2):173-180. doi:10.1097/jnr.0000000000000121

24. Lammers-van der Holst HM, Van Dongen HPA, Drosopoulos S, $\mathrm{Ga}$ K. Inter-individual differences in sleep response to shift work in novice police officers - a prospective study. Chronobiol Int. 2016;33 (6):671-677. doi:10.3109/07420528.2016.1167733

25. Fischer D, Vetter C, Oberlinner C, Wegener S, Roenneberg $\mathrm{T}$. A unique, fast-forwards rotating schedule with 12-h long shifts prevents chronic sleep debt. Chronobiol Int. 2016;33(1):98-107. doi:10.3109/07420528.2015.1113986

26. Daurat A, Foret J. Sleep strategies of 12-hour shift nurses with emphasis on night sleep episodes. Scand J Work Environ Health. 2004;30(4):299-305. doi:10.5271/sjweh.798

27. Roach GD, Dawson D, Reid KJ, Darwent D, Sargent C. The time-ofday that breaks occur between consecutive duty periods affects the sleep strategies used by shiftworkers. Chronobiol Int. 2016;33 (6):653-656. doi:10.3109/07420528.2016.1167716

28. Menna-Barreto L, Benedito-Silva AA, Moreno CRC, Fischer FM, Marques N. Individual differences in night and continuously-rotating shiftwork: seeking anticipatory rather than compensatory strategy. Ergonomics. 1993;36(1-3):135-140. doi:10.1080/0014013930 8967864

29. Petrov ME, Clark CB, Molzof HE, Johnson RL, Cropsey KL, Gamble KL. Sleep strategies of night-shift nurses on days off: which ones are most adaptive? Front Neurol. 2014;5(10):1-8. doi:10.3389/fneur.2014.00277

30. Gamble KL, Motsinger-Reif AA, Hida A, et al. Shift work in nurses: contribution of phenotypes and genotypes to adaptation. PLoS One. 2011;6(4):e18395. doi:10.1371/journal.pone.0018395

31. Schmied EA, Harrison EM, Dell'Acqua RG, Perez VG, Glickman G, Hurtado SL. A qualitative examination of factors that influence sleep among shipboard sailors. Mil Med. 2021;186(1-2):e160-e168. doi:10.1093/milmed/usaa321

32. Harrison EM, Glickman GL, Beckerley S, Taylor MK. Self-reported sleep during U.S. Navy operations and the impact of deployment-related factors. Mil Med. 2017;182(S1):189-194. doi:10.7205/MILMED-D-16-00078

33. Mantua J, Bessey A, Sowden WJ, et al. A review of environmental barriers to obtaining adequate sleep in the military operational context. Mil Med. 2019;184(7-8):e259-e266. doi:10.1093/milmed/ usz029

34. Brown CA, Berry R, Schmidt A. Sleep and military members: emerging issues and nonpharmacological intervention. Sleep Disord. 2013;2013:1-6. doi:10.1155/2013/160374

35. Saksvik IB, Bjorvatn B, Hetland H, Sandal GM, Pallesen S. Individual differences in tolerance to shift work - a systematic review. Sleep Med Rev. 2011;15(4):221-235. doi:10.1016/j. smrv.2010.07.002
36. Harrison EM, Schmied EA, Easterling AP, Yablonsky AM, Glickman GL. A hybrid effectiveness-implementation study of a multi-component lighting intervention for hospital shift workers. Int J Environ Res Public Health. 2020;17(23):9141. doi:10.3390/ijerph17239141

37. Harrison EM, Yablonsky AM, Powell AL, Ancoli-Israel S, Glickman GL. Reported light in the sleep environment: enhancement of the sleep diary. Nat Sci Sleep. 2019;11:11-26. doi:10.2147/NSS.S193902

38. Adan A, Almirall H. Horne \& Ostberg morningness-eveningness questionnaire: a reduced scale. Pers Individ Dif. 1991;12 (3):241-253. doi:10.1016/0191-8869(91)90110-W

39. Natale V, Esposito MJ, Martoni M, Fabbri M. Validity of the reduced version of the morningness-eveningness questionnaire. Sleep Biol Rhythms. 2006;4(1):72-74. doi:10.1111/j.1479-8425.2006.00192.x

40. Kaliterna L, Prizmić Z. Evaluation of the survey of shiftworkers (SOS) short version of the standard shiftwork index. Int $J$ Ind Ergon. 1998;21(3-4):259-265. doi:10.1016/S0169-8141(97)00052-8

41. Smith C, Gibby R, Zickar M, et al. Measurement properties of the shiftwork survey and standard shiftwork index. J Hum Ergol. 2001:30(1-2):191-196. doi:10.11183/jhe1972.30.191

42. Folkard S, Spelten E, Totterdell P, Barton J, Smith L. The use of survey measures to assess circadian variations in alertness. Sleep. 1995;18(5):355-361. doi:10.1093/sleep/18.5.355

43. Rosen RC, Rosekind M, Rosevear C, Cole WE, Dement WC. Physician education in sleep and sleep disorders: a national survey of U.S. medical schools. Sleep. 1993;16(3):249-254. doi:10.1093/ sleep/16.3.249

44. Jihe Kim L, Tufik S, Andersen ML. Sleep awareness and education among clinical practitioners. Clin Med. 2017;17(4):380. doi:10.7861/ clinmedicine.17-4-380

45. Saksvik-Lehouillier I, Bjorvatn B, Hetland H, et al. Individual, situational and lifestyle factors related to shift work tolerance among nurses who are new to and experienced in night work. $J$ Adv Nurs. 2013;69(5):1136-1146. doi:10.1111/j.1365-2648.2012.06105.x

46. Van Dongen HP, Maislin G, Mullington JM, Dinges DF. The cumulative cost of additional wakefulness: dose-response effects on neurobehavioral functions and sleep physiology from chronic sleep restriction and total sleep deprivation. Sleep. 2003;26(2):117-126. doi:10.1001/archsurg.2011.121

47. Rahman SA, Rood D, Trent N, Solet J, Langer EJ, Lockley SW. Manipulating sleep duration perception changes cognitive performance - an exploratory analysis. J Psychosom Res. 2020;132:109992. doi:10.1016/j.jpsychores.2020.109992

48. Reyner LA, Horne JA. Falling asleep whilst driving: are drivers aware of prior sleepiness? Int J Legal Med. 1998;111(3):120-123. doi:10.1007/s004140050131

49. Åkerstedt T, Anund A, Axelsson J, Kecklund G. Subjective sleepiness is a sensitive indicator of insufficient sleep and impaired waking function. J Sleep Res. 2014;23(3):242-254. doi:10.1111/jsr.12158

50. Lee C, Smith MR, Eastman CI. A compromise phase position for permanent night shift workers: circadian phase after two night shifts with scheduled sleep and light/dark exposure. Chronobiol Int. 2006;23(4):859-875. doi:10.1080/07420520600827160

51. Lo JC, Leong RLF, Ng ASC, et al. Cognitive effects of split and continuous sleep schedules in adolescents differ according to total sleep opportunity. Sleep. 2020;43(12):zsaa129. doi:10.1093/sleep/ zsaa129

52. Roach GD, Zhou X, Darwent D, Kosmadopoulos A, Dawson D, Sargent C. Are two halves better than one whole? A comparison of the amount and quality of sleep obtained by healthy adult males living on split and consolidated sleep-wake schedules. Accid Anal Prev. 2017;99:428-433. doi:10.1016/j.aap.2015.10.012

53. Zhou X, Sargent C, Kosmadopoulos A, Darwent D, Dawson D, Roach GD. Do split sleep/wake schedules reduce or increase sleepiness for continuous operations? Accid Anal Prev. 2017;99:434-439. doi:10.1016/j.aap.2015.10.027 
54. Short MA, Centofanti S, Hilditch C, Banks S, Lushington K, Dorrian J. The effect of split sleep schedules (6h-on/6h-off) on neurobehavioural performance, sleep and sleepiness. Appl Ergon. 2016;54:72-82. doi:10.1016/j.apergo.2015.12.004

55. Harrison EM, Gorman MR. Changing the waveform of circadian rhythms: considerations for shift-work. Front Neurol. 2012;3:72. doi:10.3389/fneur.2012.00072.

56. Walbeek TJ, Harrison EM, Soler RR, Gorman MR. Enhanced circadian entrainment in mice and its utility under human shiftwork schedules. Clocks Sleep. 2019;1(3):394-413. doi:10.3390/ clockssleep 1030032

57. Nabe-Nielsen K, Lund H, Ajslev JZ, et al. How do employees prioritise when they schedule their own shifts? Ergonomics. 2013;56(8):1216-1224. doi:10.1080/00140139.2013.815804

58. Miller NL, Tvaryanas AP, Shattuck LG. Accommodating adolescent sleep-wake patterns: the effects of shifting the timing of sleep on training effectiveness. Sleep. 2012;35:1123-1136. doi:10.5665/ sleep. 2002
59. Harrison EM, Easterling AP, Schmied EA, Hurtado SL, Glickman GL. Chronotype and self-reported sleep, alertness, and mental health in U.S. Sailors. Mil Med Res. 2021:8(1):1-3.

60. Reinke L, Özbay Y, Dieperink W, Tulleken JE. The effect of chronotype on sleepiness, fatigue, and psychomotor vigilance of ICU nurses during the night shift. Intensive Care Med. 2015;41 (4):657-666. doi:10.1007/s00134-015-3667-7

61. Park YM, Matsumoto K, Seo YJ, Shinkoda H, Park KP. Sleep in relation to age, sex, and chronotype in Japanese workers. Percept Mot Skills. 1998;87(1):199-215. doi:10.2466/pms.1998.87.1.199

62. Juda M, Vetter C, Roenneberg T. Chronotype modulates sleep duration, sleep quality, and social jet lag in shift-workers. J Biol Rhythms. 2013;28(2):141-151. doi:10.1177/0748730412475042

63. Neil-Sztramko SE, Pahwa M, Demers PA, Gotay CC. Health-related interventions among night shift workers: a critical review of the literature. Scand J Work Environ Health. 2014;40(6):543-556. doi:10.5271/sjweh.3445

\section{Publish your work in this journal}

Nature and Science of Sleep is an international, peer-reviewed, open access journal covering all aspects of sleep science and sleep medicine, including the neurophysiology and functions of sleep, the genetics of sleep, sleep and society, biological rhythms, dreaming, sleep disorders and therapy, and strategies to optimize healthy sleep.
The manuscript management system is completely online and includes a very quick and fair peer-review system, which is all easy to use. Visit http://www.dovepress.com/testimonials.php to read real quotes from published authors. 